\title{
Research on the relationship between investor network interaction and stock price fluctuation-Take "SSE e interaction" as an example
}

\author{
Ren Chunmiao $^{1}$ \\ ${ }^{1}$ Business School of Henan University, KaiFeng, China
}

\begin{abstract}
Whether the stock price fluctuation in emerging markets such as China is dominated by "information efficiency" or "noise" has aroused many scholars' disputes. Based on the "SSE e interaction" Q \& A data, this paper uses the fixed effect model to study the impact of "SSE e interaction" on the stock price synchronization from 3 perspectives: the lag of the company's response, the pertinence and the negative emotional tendency of investors. The research found that the targeted response of listed companies to investors' questions in the "SSE e interaction" significantly improved the synchronization of stock prices, and the lag of the response may be the result of selective and tendentious information dissemination. The negative sentiment of investors has certain information content, but excessive negative sentiment may bring noise to the market. Our research shows that information and "noise" coexist in China's capital market, but "noise" is still the dominant factor in stock price fluctuations.
\end{abstract}

\section{Introduction}

The emergence of the Internet, interactive media and mobile applications has greatly impacted the traditional model of information disclosure of the company. Teleconference, news report and the company's website have become important channels for investors to obtain information. However, the company's strategic use of communication tools and biased dissemination of good information may lead to information bias of investors [1], which is not conducive to the stable operation of the capital market. In 2013, the Shanghai stock exchange launched the "SSE e interaction" online investor interaction platform, which improved the company's information transparency to a certain extent. What is the impact of the implementation and interactive features of the platform on the volatility of the share price in the capital market?

Based on the "SSE e interaction " Q \& A data, this paper attempts to explain the above issues. The research found that the company's dutiful response to "SSE e interaction" can improve the market information environment, and the negative sentiment of investors has certain information content, but the extremely negative sentiment will bring "noise" to the market.

\section{Literature review}

\subsection{The role of online media in the capital market}

The popularity and wide use of the Internet has greatly impacted the traditional way of information transmission of companies. On the one hand, the Internet provides investors with direct access to the operating information of listed companies, significantly improving the information environment of investors [2]. On the other hand, by reducing information asymmetry between insiders and investors, news reports can have a binding effect on insiders who pays attention to litigation risk and closely related to personal wealth, reputation capital and insider trading [3]. Reference [4] proved that in noisy markets, information is disseminated through the Internet and mobile devices, which greatly shortens the time for investors to reach consensus and reduces market noise.

At present, the academic community has recognized the role of Internet social media on the capital market, and has basically formed a consistent view. However, the research on the quality of social media interaction is not yet mature.

\subsection{The effect of investor behavior on capital market}

The behavior of social media investors, especially individual investors, is an important factor affecting the 
stock market. The research evidence shows that in China, where the proportion of retail investors is high, the increase of individual investors' attention has had a greater impact on the stock market [5]. Investors' active information search behavior can ease the information asymmetry between the company and investors, which improve the market information environment [6].

With the continuous development of the Internet and the media, the role of individual investors has gradually shifted from the complete receiver of information to the disseminator of information. Scholars' research on this mainly focuses on investor sentiment. A research found that in China, changes in individual investor sentiment not only affect the equilibrium return of the stock market, but also have a reverse correction effect on the volatility of the stock market return [7]. These studies have shown that the sentiment expressed by investors on social media can react to the capital market, but it has not yet been determined whether this effect is beneficial or negative to the efficiency of the capital market.

\section{Theoretical analysis and research assumptions}

\subsection{Interaction quality of online platform and stock price synchronization}

By asking questions on social media and checking the information and replies released by listed companies, investors can obtain relatively reliable information about the characteristics of the companies which they care about more directly and conveniently. Compared with news reports, the interactive information of social media has overcome the "variability" problem that is easy to appear in news reports, and it is more truthful, compliant and accurate. It can provide better company information for investors' investment decisions, improve investors' information processing ability and improve market efficiency. However, although the exchange has included the interaction of social platforms of listed companies into the assessment, its role is limited. The company often turns a blind eye to investors' questions and answers too slowly, and the company's questions about the selection and tendency have not been fundamentally resolved. Investors pay too much attention to the interactive quality of the company and neglect the basic operation and management information of the company, which inevitably affects the investment decisions. The generation of "noise" alleviates the phenomenon of "rising and falling at the same time" of the stock price. At this point, assumption 1 is proposed as follows:

H1a: the interaction behavior of listed companies on Internet social media is negatively related to the stock price synchronization.

H1b: the interaction behavior of listed companies on Internet social media is positively related to the stock price synchronization.

\subsection{Synchronization of investor sentiment and stock price}

According to the prospect theory, investors' investment behavior is essentially a "decision involving risks", and their satisfaction with the unexpected returns is often less than their disappointments with the unexpected losses. As a result, investor sentiment tends to fluctuate more on negative news than on good news. Therefore, we predict that investors' emotional fluctuations may send certain messages, but their extremely negative emotions will bring noise. When the quality information is the main factor leading to the stock price fluctuations, the stock price synchronization first decreases and then increases with the increase of the negative sentiment of investors; and if "noise" occupies the dominant position in the market, the stock price synchronization first increases and then decreases with the increase of the negative sentiment of investors. Based on this, this paper proposes assumption 2:

$\mathrm{H} 2 \mathrm{a}$ : the stock price synchronization first decreases and then increases with the increase of investors' negative sentiment.

$\mathrm{H} 2 \mathrm{~b}$ : the stock price synchronization first increases and then decreases with the increase of investors' negative sentiment.

\section{Research and design}

\subsection{Sample selection and data source}

As the research object of this paper is "SSE e interaction " Q\&A data, there is no lag in the question and answer date of the website before December 2015, which is unreasonable. Therefore, this paper takes all listed companies with A share in the Shanghai stock which annual Q\&A data is more than 10 in the "SSE e interaction" "Q \& A" sectors in 2016-2018 as the initial research samples, and eliminates the samples of financial industry, ST, *ST and IPO in the current year, and finally obtains 2,427 observation samples.

\subsection{Definition of variables}

4.2.1 Interaction of "SSE e interaction": With reference to the existing research, the lag of the company's response is defined as the number of days between the date of the listed company's response and the date of the investor's question; the similarity indicator of the response is defined as the ratio of the number of common words and the number of words of the listed company's response [8].

4.2.2 Investor sentiment: This paper uses Baidu Natural Language Processing technology to deal with the questions of investors, and calculates the proportion of negative sentiment of investors, in order to measure the negative sentiment of investors. 
4.2.3 Share price synchronization: According to the existing research [9], this paper uses the individual stock yield $R_{i t}$, the market yield $R_{m t}$ and the industry yield $R_{n t}$ calculate the $R_{2}$ of model (1) , to measure individual stock yield that can be explained by market and industry factor. In order to control the impact of the range difference of data range, we use model (2) to carry out the logarithm processing of $\mathrm{R}^{2}$ and obtain the stock price synchronization indicator syn.

$$
s y n_{i t}=\ln \frac{R_{i t}^{2}}{1-R_{i t}^{2}}
$$$$
\mathrm{RET}_{\mathrm{iw}}=\beta_{0}+\beta_{1} R_{m w}+\beta_{2} R_{n w}+\varepsilon
$$

4.2.4 Other variables: With reference to the existing research [10-11], the paper selects financial leverage (lev), shareholding ratio of the first largest shareholder (first), Nature of actual controller (nsoe), company size (size), profitability of the company (roe), growth of the company $(\mathrm{mb})$, number of media reports (media), number of analysts tracked (analyst), and whether it is the 4 major international audits (Big4) as the control variables.

\subsection{Model construction}

In order to test the assumption 1, this paper constructs the model (3) as follows.

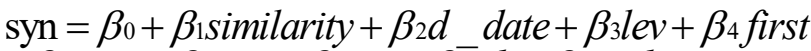
$+\beta_{5}$ nsoe $+\beta_{6 \text { size }}+\beta_{7}$ roe $+\beta_{8}$ mb $+\beta_{9}$ media + $\beta_{10}$ analysts $+\beta_{11}$ big $4+\beta_{12}$ year $+\beta_{13 \text { industry }}$

We use model (4) to test assumption 2. e egative2 equals the square of e negative.

syn $=\beta_{0}+\beta_{1}$ e_negative $+\beta_{2} e$ negative $2+\beta_{3}$ lev $+\beta_{4}$ first $+\beta_{5}$ nsoe $+\beta_{6 \text { size }}+\beta_{\text {7roe }}+\beta_{8} m b+$ $\beta_{9}$ media $+\beta_{10 \text { analysts }}+\beta_{11}$ big $4+\beta_{12}$ year + $\beta$ 13industry

\section{Results \& Discussion}

\subsection{Test results of main assumptions}

In Table I, the similarity of the company's response is positively correlated with the share price synchronization at the $10 \%$ level, while the lag of the response and the share price synchronization are positively correlated, but are not statistically significant. In column (2) - (3), the 2 coefficients of negative sentiment of investors are significantly negative, indicating that with the increase of negative sentiment of investors, the company's share price synchronization first increases and then decreases, and the results are still significant when controlling the company's interaction. This shows that the negative sentiment of investors can not only bring information to the capital market, but also may generate noise. Assumption $2 \mathrm{~b}$ holds.
TABLE I. REgRESSION RESUlTS OF MAIN ASSUMPTION TEST

\begin{tabular}{|l|l|l|l|}
\hline \multirow{2}{*}{\multicolumn{1}{c|}{ variable }} & \multicolumn{3}{c|}{ syn } \\
\cline { 2 - 4 } similarity & \multicolumn{1}{|c|}{$(\mathbf{1})$} & \multicolumn{1}{c|}{ (2) } & \multicolumn{1}{c|}{ (3) } \\
\hline d_date & $0.615^{*}$ & & $0.702^{*}$ \\
\hline e_negative & & $4.697^{* *}$ & 0.001 \\
\hline e_negative2 & & $-3.643^{*}$ & $-3.657^{* *}$ \\
\hline $\begin{array}{l}\text { control } \\
\text { variable }\end{array}$ & yes & yes & yes \\
\hline Constant & $8.635^{* * *}$ & $6.996^{* * *}$ & $6.904^{* * *}$ \\
\hline Observations & 2,427 & 2,427 & 2,427 \\
\hline R-squared & 0.408 & 0.409 & 0.411 \\
\hline $\begin{array}{l}\text { Number of } \\
\text { stock }\end{array}$ & 1,054 & 1,054 & 1,054 \\
\hline
\end{tabular}

Robust standard errors in parentheses. ${ }^{* * *} \mathrm{p}<0.01$, ** $\mathrm{p}<0.05, * \mathrm{p}<0.1$

\subsection{Further analysis: "information efficiency" or "noise" transmission}

According to the effective market theory, when the market is "information efficient", the higher the quality of information disclosure of listed companies, the lower the share price synchronization of the company. If "noise" is the dominant force of the market, the improvement of the quality of information disclosure of listed companies will improve the share price synchronization. Based on this, in order to explore the information content of China's capital market at this stage and the role of "SSE e interaction" in it, this paper uses the information disclosure evaluation results of listed companies on Shanghai Stock Exchange as the proxy variable to reflect the company's information disclosure quality, and investigates the relationship between "SSE e interaction"' interaction and stock price synchronization under different information disclosure quality levels.

With reference to the existing research [12], we divided the sample firms into 2 groups according to whether the rating result was A, the company with A rating result was regarded as the group with higher quality of information disclosure, and the company with $\mathrm{B}, \mathrm{C}$ and $\mathrm{D}$ rating result was regarded as the group with lower quality of information disclosure, and used group regression to study the relationship between interaction and stock price synchronization under different information environments.

Table II shows the results of the group regression. Column (1) and column (3) are the results of group regression of poor information environment, and column (2) and column (4) are the results of group regression of good information environment. According to table II, we found that the group regression results of investor sentiment were not significant in statistical sense, indicating that there was no significant difference in the changes of investor sentiment among companies with different information disclosure quality. The positive correlation between the lag of reply and the 
synchronization of stock price, the positive correlation between the similarity of reply and the synchronization of stock price are more significant in companies with poor quality of information disclosure. And although the company's response pertinence coefficient is not significant in the group with good information disclosure quality, its symbol has become negative. This shows that China's capital market is still full of "noise", and at "SSE e interaction", company can alleviate the impact of "noise" and improve the stock price synchronization through responding specifically.

TABLE II. GROUP REgRESSION TEST RESUlts

\begin{tabular}{|c|c|c|c|c|}
\hline \multirow{2}{*}{ variable } & \multicolumn{4}{|c|}{ syn } \\
\hline & (1) & (2) & (3) & (4) \\
\hline similarity & $0.763 * *$ & -0.069 & $0.754 * *$ & -0.071 \\
\hline d_date & $0.002 * *$ & 0.000 & $0.002 * *$ & 0.000 \\
\hline e_negative & & & -0.356 & -2.07 \\
\hline e_negative2 & & & 0.222 & 1.723 \\
\hline control variable & yes & yes & yes & yes \\
\hline Constant & -1.255 & 0.706 & -1.129 & 1.317 \\
\hline Observations & 1,792 & 635 & 1,792 & 635 \\
\hline Number of stock & 891 & 371 & 891 & 371 \\
\hline
\end{tabular}

Robust standard errors in parentheses. $* * * \mathrm{p}<0.01$, ** $\mathrm{p}<0.05, * \mathrm{p}<0.1$

\section{Robustness test}

\subsection{The endogenous problem in the model}

In view of the possible endogenous problems in the model, we selected 3 indicators as tool variables: the shareholding ratio of the first largest shareholder (first), the nature of the actual controller (nsoe) and the shareholding ratio of institutional investors (inst), and used the 2SLS regression method of tool variables to test. According to the 2SLS regression results (as shown in Table III), after solving the endogenous problem of variables, the company's recovery lag is positively correlated with the stock price synchronization at the level of $1 \%$. This shows that the company's timely response to investors' questions will reduce the synchronization of stock prices and increase market noise, which provides evidence for the company's selective and tendentious response to "SSE e interaction".

TABLE III. 2SLS REGRESSION RESULTS

\begin{tabular}{|l|l|l|l|l|}
\hline \multirow{2}{*}{ variable } & \multicolumn{4}{|c|}{ syn } \\
\cline { 2 - 5 } similarity & \multicolumn{1}{|c|}{ (1) } & \multicolumn{1}{c|}{ (3) } & \multicolumn{1}{|c|}{ (4) } \\
\hline & & $\begin{array}{l}3.271 \\
* *\end{array}$ & & $\begin{array}{l}3.264^{*} \\
* *\end{array}$ \\
\hline d_date & $\begin{array}{l}0.056^{*} \\
* *\end{array}$ & $\begin{array}{l}0.057 \\
* * *\end{array}$ & $\begin{array}{l}0.056^{*} \\
* *\end{array}$ & $\begin{array}{l}0.057^{*} \\
* *\end{array}$ \\
\hline e_negative & & & 5.355 & 4.916 \\
\hline e_negative2 & & & -4.439 & -3.87 \\
\hline
\end{tabular}

\begin{tabular}{|l|l|l|l|l|}
\hline \multirow{2}{*}{\multicolumn{1}{|c|}{ variable }} & \multicolumn{4}{|c|}{ syn } \\
\cline { 2 - 5 } & \multicolumn{1}{|c|}{$(\mathbf{1 )}$} & \multicolumn{1}{c|}{ (2) } & \multicolumn{1}{c|}{ (3) } & \multicolumn{1}{c|}{ (4) } \\
\hline $\begin{array}{l}\text { control } \\
\text { variable }\end{array}$ & yes & yes & yes & yes \\
\hline Constant & 0.882 & $\begin{array}{l}- \\
0.141\end{array}$ & -0.645 & -1.611 \\
\hline Observations & 2,427 & 2,427 & 2,427 & 2,427 \\
\hline $\begin{array}{l}\text { Number of } \\
\text { stock }\end{array}$ & 1,054 & 1,054 & 1,054 & 1,054 \\
\hline
\end{tabular}

Robust standard errors in parentheses. $* * * \mathrm{p}<0.01, * *$ $\mathrm{p}<0.05, * \mathrm{p}<0.1$

\section{2 robust test of variables}

With reference to the existing research [13], this paper remeasures the stock price synchronization with $\mathrm{R}^{2}$ calculated by the company yield and market yield on $t$ day to investigate the possible impact of the measurement form of stock price synchronization on the test results. It is found that when the measurement method of stock price synchronization is changed, our regression results are still stable.

\section{Conclusions}

Our research found that China's capital market is still an underdeveloped market with "noise" as the main driving factor. The targeted response of listed companies to investors' questions in "SSE e interaction" can increase their market information content and improve the stock price synchronization. The spread of investors' sentiment itself has certain information content, but their excessive negative sentiment will also bring noise to the market.

The policy recommendations of this paper are: (a) the exchange should continue to improve the supervision and evaluation system of the interactive platform, actively respond to and prevent the occurrence of information transmission behavior of enterprises. ( b ) When responding to investors' questions, listed companies should focus on solving prominent problems and improve the pertinence of the replies. (c) Investors should strengthen information screening ability when making investment judgments, pay more attention to the company's financial and non-financial information, and avoid emotional investment.

\section{References}

1. Yang J.H., Liu S.(2017) Accounting narratives and impression management on social media. Accounting \& Business Research (Taylor \& Francis), 47:673-694.

2. Tan S., Kan S., Cui X.Y.(2016) Can internet communication improve the efficiency of market information? -- Based on the research of "interactive easy" network platform of Shenzhen Stock Exchange. Financial Research, 03:174-188.

3. Dai L., Parwada J. T., Zhang B.(2015) The governance effect of the media's news dissemination 
role: evidence from insider trading. Journal of Accounting Research ,53:331-366.

4. Lee, M. H. , Tsai T. C., Chen J. E., Lio M. C. (2018) Can information and communication technology improve stock market efficiency? A cross-country study. Bulletin of Economic Research,71(2):113-135.

5. Shi Y., Tang J., Guo K.(2017) The impact of social media investor attention and investor sentiment on China's stock market. Journal of Central University of Finance and Economics, 07:45-53.

6. Hu W. J., Zhang K. Y.(2019) Investors' attention and market reaction of annual report inquiry letter: price pressure or information transmission. Economic Management, 41: 162-177.

7. Wang M. J., Sun J. J.(2004) China stock market earnings, earnings volatility and investor sentiment. Economic Research, 10:75-83.

8. Gong G. M., Yang L.(2018) Can good communication reduce the risk of stock price crash? Friends of Accountants, 14:30-36.
9. Roll, R. 1988.R2. The Journal of Finance, 43: 541566.

10. Wang Y. P., Liu H. L., Wu L. S.(2009) Information transparency, institutional investors and share price synchronization. Financial Research, 12:162-174.

11. Huang J., Guo Z. R.(2014) News media coverage and capital market pricing efficiency - based on the analysis of stock price synchronization. Management World, 05:121-130.

12. Ji Z. B., Zang R. H.(2019) Can the opening of capital market improve the stability of stock price?: Based on the empirical evidence of the Shanghai Hong Kong stock connect. World Economic Research, 05: $14-26+52+134$

13. Zhu H. J., He X. J., Tao L.(2007) Can China's securities analysts improve the efficiency of the capital market -- Based on the empirical evidence of stock price synchronization and stock price information content. Financial Research, 02:110-121. 